\title{
O que sabem os utentes sobre antibióticos: um estudo de investigação em duas Unidades de Saúde Familiar
}

Helena Luísa Lopes,* João Brites Pereira,** Manuela R. Carvalho**

\section{RESUMO}

Objetivo: Caracterizar os conhecimentos dos utentes de duas Unidades de Saúde Familiar (USF) acerca da utilização de antibióticos.

Tipo de estudo: Estudo observacional e transversal, com componente analítica.

Local: USF das Conchas e Ars Médica.

População: Utentes inscritos nas USF das Conchas e Ars Médica com 18 ou mais anos de idade $(n=20.776)$.

Métodos: Questionário anónimo aplicado a uma amostra de 380 utentes. Variáveis medidas: idade, sexo, escolaridade, nacionalidade, existência de filhos menores de 18 anos, conhecimentos sobre o uso de antibióticos e sua utilização sem prescrição médica. Resultados: A maioria era do sexo feminino (68,95\%), tinha pelo menos o $12 .{ }^{\circ}$ ano e nacionalidade portuguesa. Média de idades de 46 anos. Menos de metade tinha filhos menores de 18 anos (42,37\%). A maioria (65,26\%) respondeu que os antibióticos não servem para tratar tosse, dores no corpo, dor de garganta e «nariz a pingar» com a duração de cinco dias e $63,42 \%$ responderam que os antibióticos servem para tratar infeções causadas por bactérias. Menos de metade $(48,98 \%)$ refere que os antibióticos não ajudam a recuperar mais rápido de uma gripe ou constipação. A maioria $(67,89 \%)$ identificou a utilização de antibióticos como origem de infeções resistentes. No entanto, $17,11 \%$ dos utentes já tomou antibióticos sem prescrição médica. Verificou-se uma correlação fraca positiva entre a escolaridade e o número de respostas certas $\left(r_{s}=0,328\right)$. Os utentes que não se automedicaram responderam mais corretamente às questões (teste de Mann-Whitney $p=0,002$ ).

Conclusão: Em geral, os utentes demonstraram conhecimentos superiores aos descritos na literatura portuguesa, possivelmente por se tratar de uma amostra com elevada escolaridade. A prevalência de automedicação esteve de acordo com os dados da literatura. Este estudo permitiu melhorar a perceção sobre os conhecimentos dos utentes em relação ao uso de antibióticos, bem como alertar para a automedicação como um problema de elevada prevalência.

Palavras-chave: Antibióticos; Conhecimento; Utentes.

\section{INTRODUÇÃO}

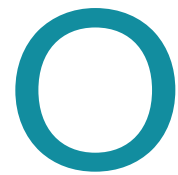

desenvolvimento de vacinas e fármacos que previnem e curam infeções bacterianas foi uma das maiores contribuições do século XX para a longevidade e qualidade de vida humanas. ${ }^{1}$

Os antibióticos encontram-se entre as medicações mais prescritas, sendo utilizados para combater infeções bacte-

Médicos internos de Medicina Geral e Familiar.

*USF das Conchas.

**USF Ars Médica. rianas. No entanto, a utilização em situações em que não estão indicados é um dos principais fatores para o desenvolvimento de estirpes resistentes. ${ }^{2}$ Com a redução da sua eficácia aumenta a necessidade de consultas médicas, exames complementares de diagnóstico, prescrição de medicamentos adicionais e mesmo de internamento hospitalar. ${ }^{2}$

O uso racional de agentes antibióticos depende da compreensão dos seus mecanismos de ação e características farmacológicas, dos mecanismos das resistências bacterianas e das estratégias que podem ser usadas para limitar essas resistências. ${ }^{1}$ 
A decisão da prescrição do antibiótico é da responsabilidade do médico, mas pode ser influenciada por vários fatores, nomeadamente as expectativas dos doentes e o conhecimento destes sobre a utilização dos antimicrobianos..$^{3-5}$ A automedicação com antibióticos é frequente e é considerada um dos fatores que mais contribui para o seu uso inadequado. ${ }^{6}$ Uma revisão sistemática baseada em 35 estudos de base populacional, realizados em todos os continentes de 1970 a 2009, mostrou que a taxa de automedicação com antibióticos varia de 3 a $100 \%,{ }^{7}$ sendo menor nos países onde existem políticas mais rigorosas de controlo de venda destes fármacos sem receita médica. ${ }^{8}$ Em Portugal foram realizados dois estudos que avaliaram a prevalência da automedicação com antibióticos: um no concelho de Vizela, onde foi obtida uma prevalência de $4 \%$; $^{2}$ e outro no Algarve, onde foi obtida uma prevalência de 18,9\% (17-21\%, IC 95\%). . No entanto, desconhecem-se dados com representatividade nacional.

Para alertar a população para este tema foram implementadas campanhas de sensibilização a nível nacional, a mais recente aplicada sazonalmente desde 2011 pela Direção-Geral da Saúde, denominada "Antibióticos a mais, saúde a menos". O presente estudo tem como objetivo caracterizar os conhecimentos dos utentes de duas Unidades de Saúde Familiar (USF) acerca da utilização de antibióticos.

\section{MÉTODOS}

Tratou-se de um estudo observacional e transversal, com componente analítica.

A população do estudo consistiu nos utentes inscritos nas USF das Conchas e Ars Médica com 18 ou mais anos de idade, num total de 20.776 utentes.

O questionário foi aplicado a uma amostra de conveniência de 380 utentes da população em estudo, constituída por utilizadores das USF Ars Médica e Conchas, com idade superior a 18 anos, que aceitaram responder ao questionário. Apesar de se tratar de uma amostra de conveniência, foi determinada a dimensão que seria necessária se a amostra fosse aleatória através do sistema OpenEpi® para um nível de confiança de $95 \%$, sendo o valor encontrado usado como referência.

Foram excluídos os utentes com incapacidade de compreensão da língua portuguesa escrita ou iliteracia.

As variáveis medidas no estudo foram: idade, sexo, escolaridade, nacionalidade, existência de filhos menores de 18 anos, conhecimentos sobre o uso de antibióticos e a sua utilização sem prescrição médica.

Os dados foram obtidos através da aplicação de um questionário elaborado pelos autores (Anexo I), tendo por base estudos com objetivos semelhantes. ${ }^{2,10-12}$ O questionário, de autopreenchimento anónimo e em formato papel, foi entregue pelas secretárias clínicas aquando da receção dos utentes. Após o preenchimento, os questionários foram colocados pelos próprios utentes em caixas fechadas designadas para o efeito. A aplicação do questionário realizou-se durante os meses de maio, junho e julho de 2014.

Apesar de não validado, o questionário foi submetido a um teste piloto realizado a 38 utentes ( $10 \%$ da amostra). Os questionários foram entregues e no final foram inquiridos os respondentes acerca de dúvidas ou dificuldades no preenchimento, o que permitiu identificar possíveis fontes de vieses ao nível da interpretação do mesmo. Desta forma, foram efetuadas alterações de caráter gramatical ao questionário para melhorar a sua compreensão, tendo sido descartados os questionários aplicados no teste piloto.

De modo a arquivar e tratar os dados recolhidos foi criada uma base de dados informática para o efeito. Foi realizada uma análise descritiva para caracterização da amostra e das respostas corretas. Foram consideradas corretas as seguintes respostas: pergunta 6 ("Não"); pergunta 7 ("Para tratamento de infeções provocadas por bactérias"); pergunta 8 (“Não"); pergunta 9 (“Sim”). As respostas às perguntas 6, 8 e 9 com mais de uma alínea assinalada foram consideradas nulas. Na questão 7 foram incluídas todas as opções assinaladas na caracterização das respostas, mesmo perante respostas múltiplas, mas apenas foram incluídas na análise do número de respostas corretas as que assinalavam isoladamente a resposta “infeções causadas por bactérias".

Aplicou-se o coeficiente de correlação de Spearman para correlacionar a variável número de respostas corretas com as variáveis idade e escolaridade, uma vez que estas não mostraram uma distribuição normal no teste de Kolmogorov-Smirnov.

Foi utilizado o teste de Mann-Whitney para avaliar a relação entre a variável automedicação e as variáveis escolaridade, existência de filhos menores de 18 anos e número de respostas corretas, tendo em consideração que as mesmas não tinham uma distribuição normal segundo o teste de Kolmogorov-Smirnov. Pelo mesmo motivo 


\begin{tabular}{|c|c|c|}
\hline Escolaridade & $\mathbf{N}$ & $\%$ \\
\hline Até ao $4 .^{\circ}$ ano & 26 & 6,84 \\
\hline Até ao $6 .^{\circ}$ ano & 26 & 6,84 \\
\hline Até ao $9 .^{\circ}$ ano & 36 & 9,47 \\
\hline Até ao $12 .^{\circ}$ ano & 102 & 26,84 \\
\hline Curso profissional & 44 & 11,58 \\
\hline Curso universitário & 144 & 37,89 \\
\hline Não respondeu & 2 & 0,53 \\
\hline Nacionalidade & $\mathbf{N}$ & $\%$ \\
\hline Portugal & 353 & 92,89 \\
\hline Brasil & 10 & 2,63 \\
\hline Angola & 7 & 1,84 \\
\hline Outros & 8 & 2,11 \\
\hline Não respondeu & 2 & 0,53 \\
\hline
\end{tabular}

foi também usado o teste de Mann-Whitney para avaliar a relação entre a variável número de respostas corretas e as variáveis existência de filhos menores de 18 anos e sexo.

O protocolo do presente estudo foi submetido à apreciação da Comissão de Ética para a Saúde da ARS LVT, que deu parecer favorável à sua realização. Ao preencher o questionário, os utentes deram consentimento informado de uma forma tácita. O trabalho não foi submetido à Comissão Nacional de Proteção de Dados, visto os questionários terem um caráter anónimo.

\section{RESULTADOS}

A colheita dos questionários manteve-se até obter a dimensão de amostra calculada inicialmente de 380 utentes, metade de cada unidade. Destes, 262 $(68,95 \%)$ eram do sexo feminino. A média de idades foi de 46 anos (IC 95\% 44,39 -47,61), com um mínimo de 18 e um máximo de 89 anos. Cerca de 37,89\% tinha curso universitário, seguido de $26,84 \%$ com o $12 .^{\circ}$ ano (Quadro I). Cerca de $92,89 \%$ era de nacionalidade portuguesa e $57,63 \%$ não tinha filhos menores de 18 anos.
O número médio de respostas corretas nas quatro perguntas que pretendiam avaliar os conhecimentos dos utentes foi 2,36 .

Relativamente aos sintomas, $65,26 \%$ respondeu que os antibióticos não servem para tratar tosse, dores no corpo, dor de garganta e «nariz a pingar» com a duração de cinco dias (Figura 1).

Cerca de $63,42 \%$ respondeu que se usa o antibiótico para tratar as infeções causadas por bactérias (Figura 2).

Relativamente à utilidade dos antibióticos na recuperação de uma gripe ou constipação, as opiniões dividemse: $48,98 \%$ refere que os antibióticos não ajudam a recuperar mais rápido de uma gripe ou constipação, enquanto $40,79 \%$ considera que "sim" ou “às vezes" (Figura 3 ).

Em relação à questão das resistências, $67,89 \%$ respondeu corretamente que a utilização de antibióticos é origem possível de infeções resistentes (Figura 4).

No que diz respeito à automedicação, $17,11 \%$ dos utentes referiu já ter tomado antibiótico sem prescrição médica. Os motivos mais frequentemente apontados foram "Amigdalite/dor de garganta" e "Dor de dentes" (Quadro II).

Não se verificou relação entre a idade e o número de respostas corretas (coeficiente de correlação de Spearman $r_{s}=0,094$ ). Verificou-se uma correlação fraca positiva entre a escolaridade e o número de respostas certas (coeficiente de correlação de Spearman $r_{s}=0,328$ ).

Não foi verificada relação entre as variáveis automedicação e escolaridade (teste de Mann-Whitney $p=0,374$ ), nem entre a automedicação e a existência de filhos menores de 18 anos (teste de Mann-Whitney $p=0,147$ ).

Houve maior número de respostas corretas no grupo de utentes que não se automedicou, com uma média de

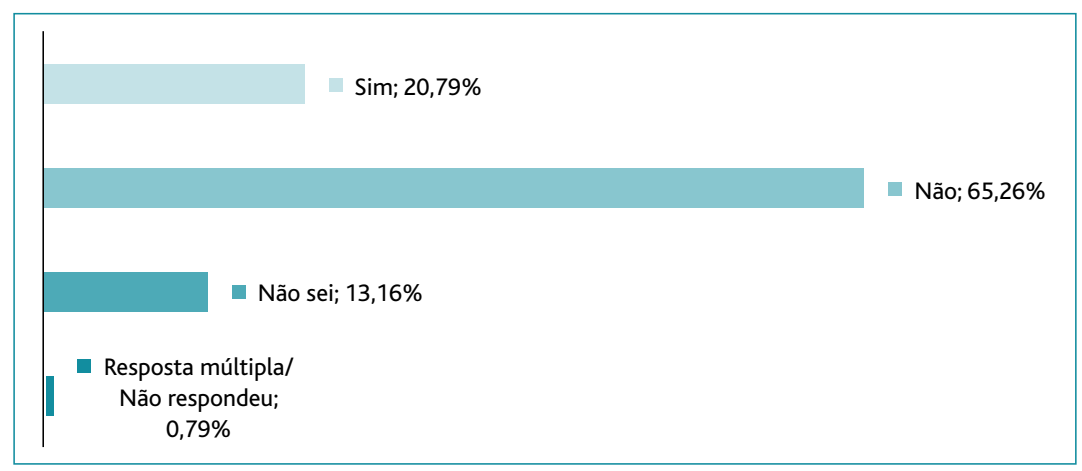

Figura 1. Respostas à questão "Os antibióticos servem para tratar tosse, dores no corpo, dor de garganta e «nariz a pingar» que duram há 5 dias?" 
2,46 respostas certas, em relação ao grupo que se automedicou que obteve uma média de 1,93 respostas corretas (teste de Mann-Whitney $p=0,002$ ).

Não foi encontrada relação entre o número de respostas corretas e a existência de filhos menores de 18 anos (teste de Mann-Whitney $p=0,359$ ), nem diferenças entre os sexos no que concerne ao número de respostas corretas (teste de Mann-Whitney $p=0,156$ ).

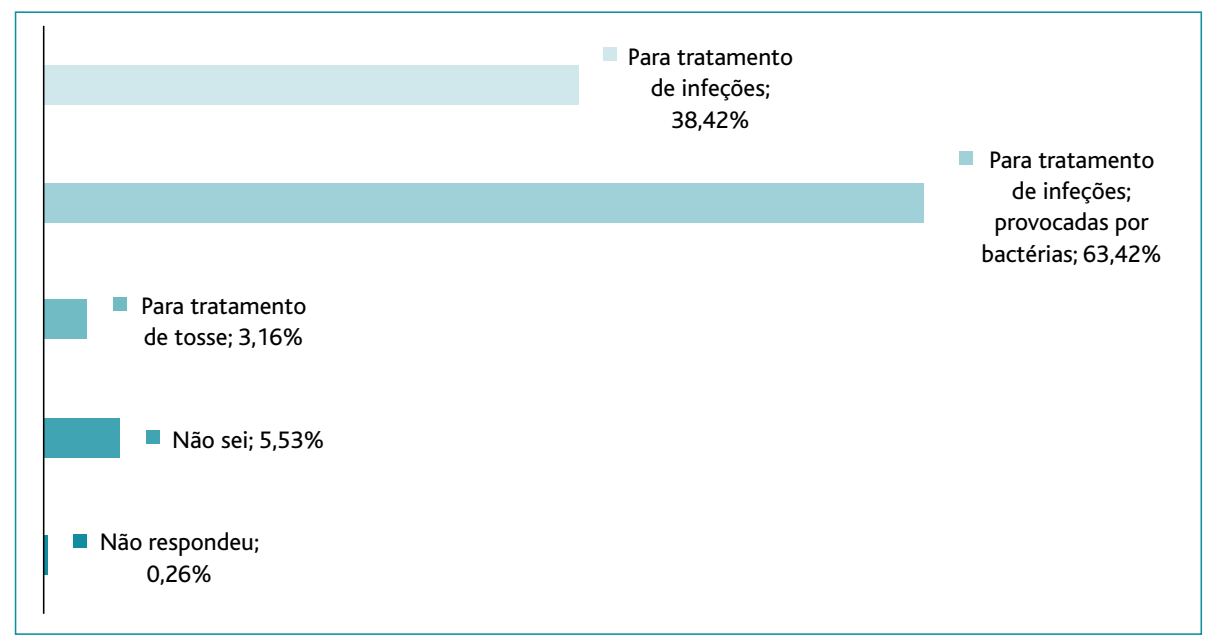

Figura 2. Respostas à questão "Para que efeitos se usa o antibiótico?"

\section{DISCUSSÃO}

Este estudo permitiu-nos avaliar alguns conhecimentos dos utentes destas USF acerca do uso de antibióticos.

A proporção de licenciados na população é inferior à dos respondentes. A média de idades da população, aproximadamente 50 anos, é superior à da amostra. Desta forma, o perfil dos respondentes corresponde a um grupo de utentes jovens, com elevada escolaridade, que poderá não ser representativo da população das unidades em estudo.

Na questão relativa ao tratamento de sintomas gripais, a percentagem de respostas erradas $(20,79 \%)$ foi considera-

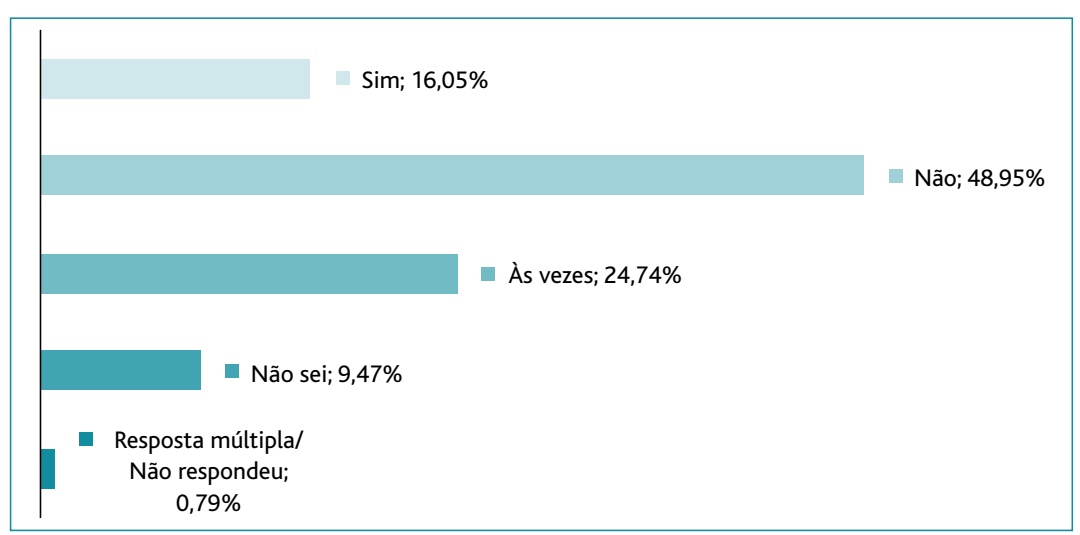

Figura 3. Respostas à questão "Os antibióticos ajudam a recuperar mais rápido de uma gripe ou constipação?"

velmente inferior à encontrada num estudo realizado nos Estados Unidos da América, em que $61 \%$ respondeu que os antibióticos servem para tratar a tosse, odinofagia e rinorreia incolor com a duração de cinco dias. ${ }^{10}$

Já a proporção de utentes que respondeu corretamente, que os antibióticos tratam infeções bacterianas $(63,42 \%)$, foi muito superior à verificada num estudo português realizado em Vizela, em que apenas 7,9\% respondeu corretamente. ${ }^{2}$ No entanto, um estudo realizado na Malásia obteve uma percentagem superior de respostas corretas (76,7\%). ${ }^{11}$ Esta discrepância poderá dever-se ao facto dos inquiridos no estudo realizado em Vizela terem uma escolaridade inferior, além de refletirem uma realidade local de um meio predominantemente rural.
Relativamente à utilidade dos antibióticos na recuperação de uma gripe ou constipação, a percentagem de respostas erradas $(40,79 \%)$ foi inferior à encontrada num estudo português realizado em Matosinhos em 2003 $(59,3 \%) .{ }^{13}$ No entanto, foi semelhante à encontrada em dois estudos internacionais, um realizado na Malásia $(38 \%)^{11}$ e outro no Reino Unido (38\%). ${ }^{12}$ A diferença encontrada entre o presente estudo e o realizado em Matosinhos pode dever-se também à menor escolaridade dos inquiridos neste último, em que 53,89\% tinha o ensino primário ou inferior.

A fração de utentes que identificou corretamente a utilização de antibióticos como origem possível de infeções resistentes $(67,89 \%)$ foi superior à encontrada no estudo de Vizela $(45,2 \%)^{2}$ e também à encontrada no estu- 


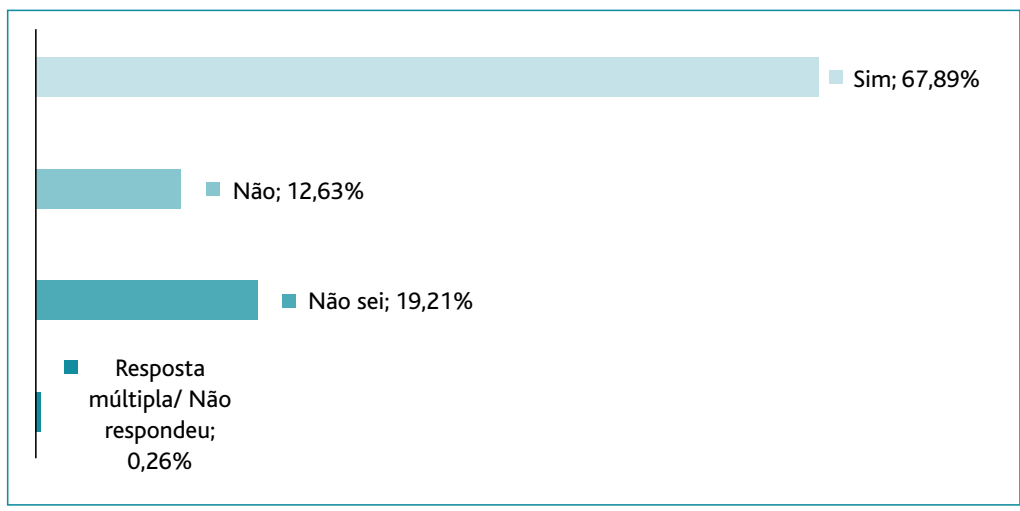

Figura 4. Respostas à questão "A utilização de antibióticos pode originar infeções resistentes?"

\begin{tabular}{|c|c|}
\hline \multicolumn{2}{|c|}{$\begin{array}{l}\text { QUADRO II. Motivos mais frequentemente apontados } \\
\text { para toma de antibiótico sem prescrição médica }\end{array}$} \\
\hline Motivos de automedicação com antibiótico & $\mathbf{N}$ \\
\hline "Amigdalite/dor de garganta" & 6 \\
\hline "Dor de dentes" & 6 \\
\hline "Tratamento habitual para os mesmos sintomas" & 5 \\
\hline "Infeção urinária" & 4 \\
\hline "Constipação" & 4 \\
\hline "Febre" & 4 \\
\hline "Tosse" & 3 \\
\hline "Em férias/estrangeiro" & 2 \\
\hline "Gripe" & 2 \\
\hline "Recomendação de familiar/amigo" & 2 \\
\hline
\end{tabular}

do realizado na Malásia (59,1\%). ${ }^{11}$ Apesar disso, foi inferior à de um estudo realizado no Reino Unido, ${ }^{12} \mathrm{em}$ que praticamente toda a amostra identificou os antibióticos como fonte de possíveis resistências bacterianas. Esta disparidade pode dever-se à existência de campanhas mais intensivas para o uso racional dos antibióticos junto da população do Reino Unido. ${ }^{14}$

De uma forma geral, é possível afirmar que os doentes inquiridos no presente estudo responderam mais acertadamente às questões do que seria expectável, tendo em conta os estudos portugueses já existentes, diferença que pode ser justificada pelo facto de se tratar de uma amostra com um elevado nível de escolaridade. No entanto, as disparidades nos resultados obtidos nas di- ferentes perguntas sugerem que a maioria dos utentes não identifica as gripes e constipações como infeções de etiologia viral.

Quando comparadas com estudos internacionais, as diferenças socioculturais e políticas entre as populações estudadas são também um importante fator a considerar, já que os diferentes países têm diferentes sistemas de saúde bem como diferentes políticas de educação para a saúde e de restrição de acesso aos antibióticos.

Relativamente à automedicação, a percentagem de utentes que admitiu já ter tomado antibiótico sem prescrição médica $(17,11 \%)$ foi superior à encontrada no estudo realizado no Reino Unido (5\%). ${ }^{6}$ No entanto, esta percentagem está de acordo com o resultado obtido no estudo realizado no Algarve $(18,9 \% \text {, IC } 95 \% 17-21 \%)^{9}$ e com um estudo pan-europeu que demonstrou que a automedicação com antibióticos varia entre $0,1 \%$ e $21 \%$ e é superior nas regiões sul e leste da Europa. ${ }^{15}$ Ainda que a automedicação com antibióticos pareça ter vários fatores de influência, ${ }^{12}$ é de referir que a discrepância encontrada relativamente ao Reino Unido pode ser explicada pela proibição absoluta da venda de antibióticos sem receita médica nas farmácias deste país, o mesmo acontecendo noutros países do norte da Europa. Em Portugal, a aquisição destes fármacos nas farmácias é, por vezes, facilitada sem receita médica.

No estudo realizado em Vizela, ${ }^{2}$ também as amigdalites, dores de garganta, gripes, dores de dentes e infeções urinárias constituíram os principais motivos reportados de toma de antibióticos sem prescrição médica.

Tal como no presente estudo, dois estudos internacionais referem a existência de uma relação entre a escolaridade e os conhecimentos demonstrados pelos utentes. ${ }^{11-12}$ Já a ausência de relação entre a variável número de respostas corretas e as variáveis idade e sexo também se constatou no estudo português realizado em Vizela. ${ }^{2}$

Apesar dos pais de crianças e adolescentes menores terem, à partida, um contacto mais frequente com os cuidados de saúde, tratando-se de uma faixa etária em que as infeções são particularmente frequentes, não foi identificada uma relação entre a existência de filhos menores de 18 anos e o nível de conhecimentos ou a automedicação. Esta situação pode espelhar uma possível falha na eficácia da educação para a saúde destas famílias. 
A relação inversa encontrada entre o número de respostas corretas e a automedicação sugere que um maior grau de conhecimentos acerca da utilização dos antibióticos poderá constituir um fator protetor no que concerneà sua utilização autónoma por parte dos utentes. No entanto, não foram encontrados dados publicados relativos a esta relação comparáveis com os do presente estudo.

Em comparação com a população estudada no Reino Unido, ${ }^{12} \mathrm{o}$ conhecimento acerca das resistências bacterianas é ainda limitado.

Como limites do estudo, salienta-se o facto de ter sido usada uma amostra de conveniência, em que a maioria dos utentes que aceitou responder ao questionário tem pelo menos o $12 .^{\circ}$ ano, não se tratando portanto de uma amostra representativa da população das unidades de saúde estudadas. Por outro lado, o questionário utilizado não foi validado, apesar de ter sido realizado um teste piloto que permitiu a sua aferição para utilização no estudo.

Seria interessante aprofundar o estudo da relação entre os conhecimentos dos utentes e as suas atitudes no que diz respeito ao uso dos antibióticos, bem como a influência direta das campanhas de informação na realidade da população portuguesa.

Apesar das limitações, este estudo permitiu melhorar a perceção sobre os conhecimentos dos utentes em relação ao uso de antibióticos de forma a eventualmente poderem aplicar-se estratégias de educação para a saúde nas USF, bem como alertar para o risco da automedicação com estes medicamentos.

\section{AGRADECIMENTOS}

Os autores agradecem às secretárias clínicas das unidades:

Alda Maria João Quaresma

Ana Paula Pinto Fulgêncio Maximiano

Fernanda Maria Brito Abreu

Maria Emília Miranda Nogueira

Maria Rosália Fernandes Baptista Bagulho

Marta Sofia Barros Teixeira Pereira Antunes

Marília Henriques Filipe

Odete Cristina Magalhães Lourenço Lopes

Rosa Maria Nogueira Anjos

Sónia Raquel Conde Neves

A sua participação foi indispensável na recolha de dados.

\section{REFERÊNCIAS BIBLIOGRÁFICAS}

1. Archer GL, Polk RE. Treatment and prophylaxis of bacterial infections. In Kasper D, Fauci A, Hauser S, Longo D, Jameson J, Loscalzo J, editors. Harrison's principles of internal medicine. 19th ed. New York: McGraw-Hill; 2015. p. 851-64. ISBN 9780071802154
2. Ribeiro M, Pinto I, Pedrosa C. Comportamento da população do concelho de Vizela no consumo de antibióticos [Antibiotics consumption behaviour of the Vizela's region population]. Rev Port Saude Publica. 2009;27(2):57-70. Portuguese

3. Currie J, LinW, ZhangW. Patient knowledge and antibiotic abuse: evidence from an audit study in China. J Health Econ. 2011;30(5):933-49.

4. World Health Organization. WHO global strategy for containment of antimicrobial resistance [Internet]. Geneva:WHO; 2001 [cited 2013 Dec 2]. Available from: http://www.who.int/drugresistance/WHO_Global_Strategy_English.pdf

5. Kickbusch I, Pelikan JM, Apfel F, Tsouros AD, editors. Health literacy: the solid facts [Internet]. Copenhagen:World Health Organization; 2013 [cited 2015 Jul 8]. ISBN 9789289000154.Available from: http://www.euro.who.int/_data/assets/pdf_file/0008/190655/e96854.pdf

6. Llor C, Cots JM. The sale of antibiotics without prescription in pharmacies in Catalonia, Spain. Clin Infect Dis. 2009;48(10):1345-9.

7. Morgan DJ, Okeke IN, Laxminarayan R, Perencevich EN, Weisenberg S. Non-prescription antimicrobial use worldwide: a systematic review. Lancet Infect Dis. 2011;11(9):692-701.

8. McKee MD, Mills L, Mainous AG 3rd. Antibiotic use for the treatment of upper respiratory infections in a diverse community. J Fam Pract. 1999;48(12):993-6.

9. Ramalhinho I, Cordeiro C, Cavaco A, Cabrita J. Assessing determinants of selfmedication with antibiotics among Portuguese people in the Algarve Region. Int J Clin Pharm. 2014;36(5):1039-47.

10. Mainous AG 3rd, Zoorob RJ, Oler MJ, Haynes DM. Patient knowledge of upper respiratory infections: implications for antibiotic expectations and unnecessary utilization. J Fam Pract. 1997;45(1):75-83.

11. Ling Oh A, Hassali MA, Al-Haddad MS, Syed Sulaiman SA, Shafie AA, Awaisu A. Public knowledge and attitudes towards antibiotic usage: a cross-sectional study among the general public in the state of Penang, Malaysia. J Infect Dev Ctries. 2011;5(5):338-47.

12. McNulty CA, Boyle P, Nichols T, Clappison P, Davey P. Don't wear me out: the public's knowledge of and attitudes to antibiotic use. J Antimicrob Chemother. 2007;59(4):727-38.

13. Mateus A. Infecções respiratórias superiores: conhecimentos sobre a doença, auto-cuidados e recurso aos serviços de saúde [Upper respiratory tract infections: knowledge about the disease, self-care and use of health services]. Rev Port Clin Geral. 2003;19(5):415-26. Portuguese

14. Public Health England.Antibiotic Guardian pledge [Internet]. London: Public Health England; 2015 [cited 2015 Jul 8]. Available from: https://antibioticguardian.com/

15. Grigoryan L, Burgerhof JG, Haaijer-Ruskamp FM, Degener JE, Deschepper R, Monnet DL, et al. Is self-medication with antibiotics in Europe driven by prescribed use? J Antimicrob Chemother. 2007;59(1):152-6.

\section{CONFLITO DE INTERESSES}

Os autores declaram não ter conflitos de interesses.

\section{COMISSÃO DE ÉTICA}

Estudo realizado após parecer favorável da Comissão de Ética para a Saúde da ARS Lisboa e Vale do Tejo.

\section{ENDEREÇO PARA CORRESPONDÊNCIA \\ Helena Luísa Lopes \\ E-mail: hlmlopes@gmail.com}

Recebido em 29-09-2014

Aceite para publicação em 24-08-2015 


\section{ABSTRACT}

\section{WHAT PATIENTS KNOW ABOUT ANTIBIOTICS: A CROSS-SECTIONAL STUDY IN TWO FAMILY HEALTH UNITS}

Objectives: To assess patient knowledge about antibiotic use in two Family Health Units (FHU).

Type of study: Cross-sectional study.

Setting: FHU das Conchas and Ars Médica.

Participants: Registered patients in the FHU das Conchas and Ars Médica 18 years of age or older.

Methods: An anonymous questionnaire was administered to a sample of 380 patients. We collected data on age, gender, education, nationality, children under 18 years, knowledge about the use of antibiotics, and their use without prescription.

Results: Most subjects were female (68.95\%), had at least 12 years of education, and were Portuguese. The average age was 46 years. Less than half had children under the age of $18(42.37 \%)$. The majority $(65.26 \%)$ responded that antibiotics are not intended to treat cough, body aches, sore throat and 'runny nose' with a duration of five days, and $63.42 \%$ responded that antibiotics are used to treat infections caused by bacteria. Less than half (48.98\%) reported that antibiotics do not help to recover faster from a cold or flu. The majority (67.89\%) identified the use of antibiotics as a cause of resistant infections. However, $17.11 \%$ had taken antibiotics without a prescription. There was a weak positive correlation between education and the number of correct responses $\left(r_{s}=0.328\right)$ ). Patients who did not self-medicate had higher knowledge scores (Mann-Whitney $\left.p=0.002\right)$. Conclusion: These patients demonstrated greater knowledge of antibiotic use compared to previous findings in the Portuguese literature. This may be due to the high level of education in the sample. The prevalence of self-medication was similar to that previously reported in the literature. This study has improved our perception of our patients' knowledge of antibiotic use, and has drawn attention to the problem of self-medication.

Keywords: Antibiotics; Knowledge; Patients.

\section{ANEXO I}

\section{Questionário}

Estamos a realizar um trabalho sobre os conhecimentos da população em relação ao uso de antibióticos. Pedimos a sua colaboração no preenchimento deste questionário anónimo e agradecemos que o coloque na caixa identificada existente na sala de espera.

1. Idade: anos

2. Sexo: $\square$ Feminino $\square$ Masculino

3. Escolaridade:
$\square$ até ao $4 .^{\circ}$ ano
até ao $6 .^{\circ}$ ano
até ao $9 .^{\circ}$ ano
$\square$ até ao $12 .^{\circ}$ ano
Curso profissional
Curso universitário

4. Nacionalidade:

5. Tem filhos menores de 18 anos? $\square \operatorname{Sim} \square$ Não

6. Os antibióticos servem para tratar tosse, dores no corpo, dor de garganta e «nariz a pingar» que duram há 5 dias?
Sim
Não
Não sei

7. Para que efeitos se usa o antibiótico?
$\square$ Para tratamento de infeções
Para tratamento de infeções provocadas por bactérias
Para tratamento de tosse
Não sei

8. Os antibióticos ajudam a recuperar mais rápido de uma gripe ou constipação?
$\square \operatorname{Sim}$
Não
Às vezes
Não sei

9. A utilização de antibióticos pode originar infeções resistentes?
$\square \operatorname{Sim}$
Não
Não sei

10. Já tomou antibiótico sem prescrição médica?

$\square \operatorname{Sim} \square$ Não

11. Se respondeu SIM à questão anterior, qual foi o motivo? 